\title{
Pooled Analysis of Tanezumab Efficacy and Safety with Subgroup Analyses of Phase III Clinical Trials in Patients with Osteoarthritis Pain of the Knee or Hip [Corrigendum]
}

Tive L, Bello AE, Radin D, et al. J Pain Res. 2019;12:975 -995 .

The authors have advised there is an error in the middle panels of Figure 6 on page 985. Both panels read "Patients with severe OA" the panel on the right should read "Patients with less severe OA".

The correct Figure 6 is shown below.

Diabetic patients

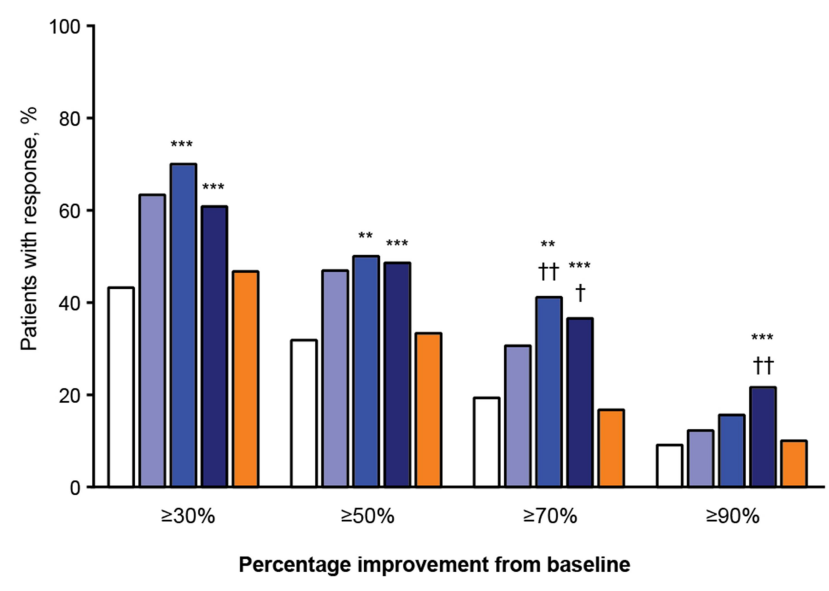

Patients with severe OA

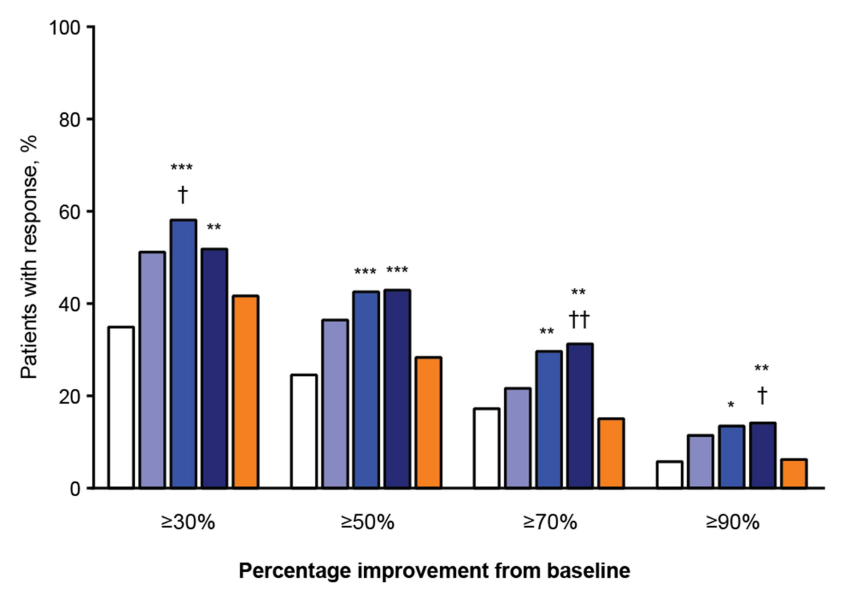

Figure 6 Continued.
Non-diabetic patients

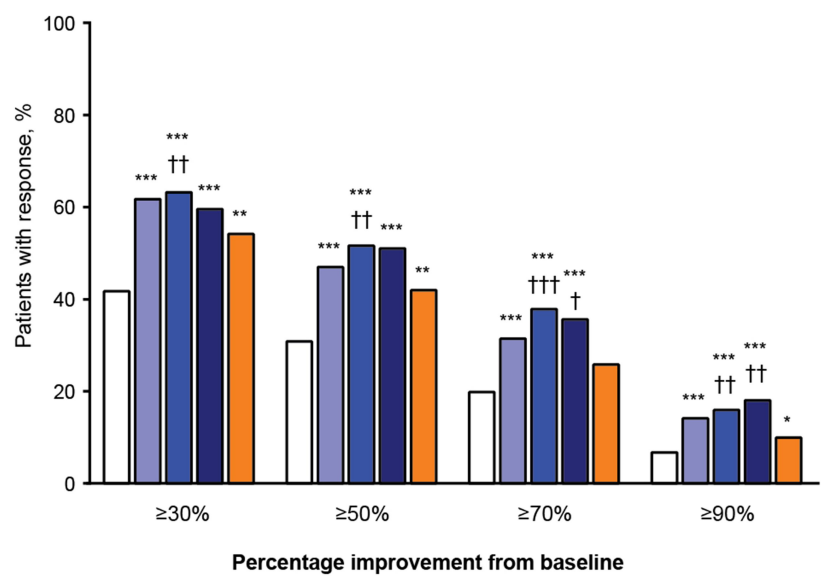

Patients with less severe OA

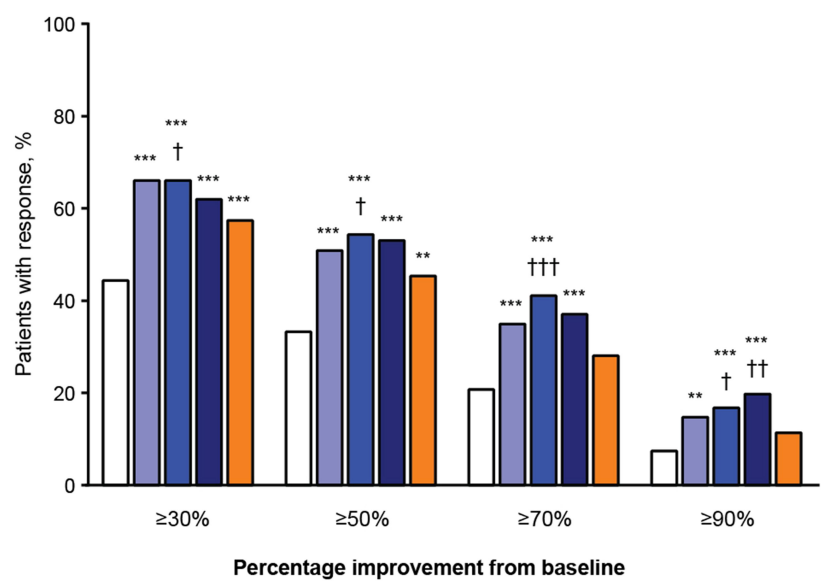


Patients aged $\geq 65$ years

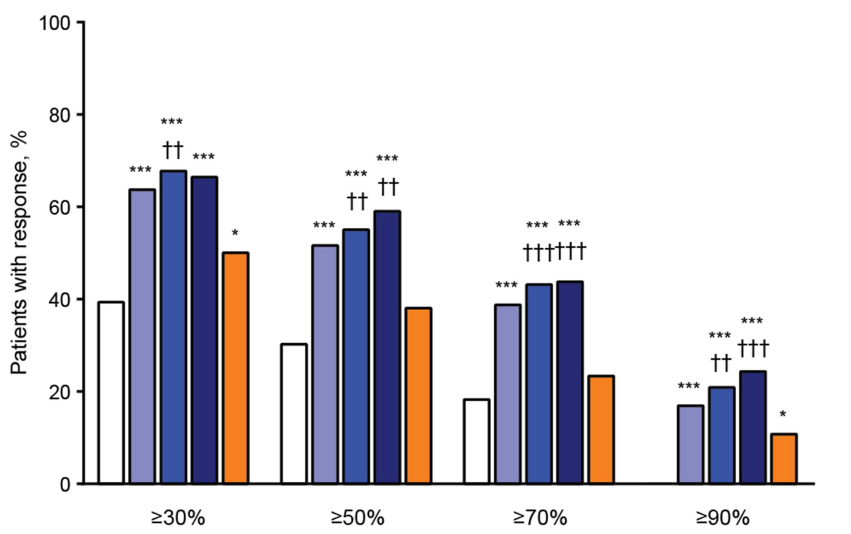

Percentage improvement from baseline
Patients aged $<65$ years

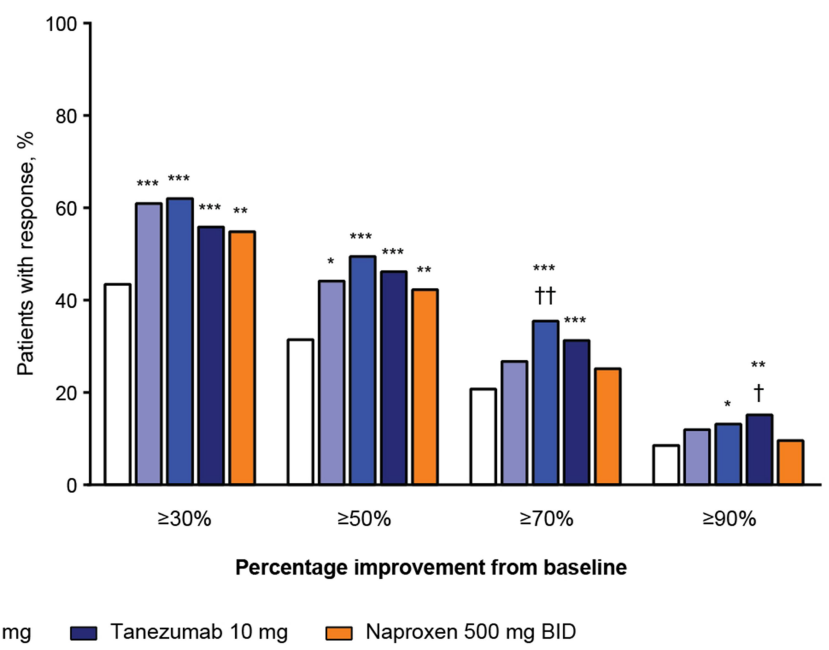

Figure 6 Percentage of patients with $\geq 30 \%, \geq 50 \%, \geq 70 \%$, and $\geq 90 \%$ improvement on the WOMAC pain subscale at week 16 in the subgroups. Notes: $* P \leq 0.05 ; * * P \leq 0.01 ; * * * P \leq 0.001$ vs placebo. ${ }^{\dagger} P \leq 0.05 ;{ }^{\dagger} P \leq 0.01$; ${ }^{\dagger \dagger} P \leq 0.001$ vs naproxen.

Abbreviations: BID, twice daily; OA, osteoarthritis; WOMAC, Western Ontario and McMaster Universities Osteoarthritis Index.

\section{Publish your work in this journal}

The Journal of Pain Research is an international, peer reviewed, open access, online journal that welcomes laboratory and clinical findings in the fields of pain research and the prevention and management of pain. Original research, reviews, symposium reports, hypothesis formation and commentaries are all considered for publication. The manuscript management system is completely online and includes a very quick and fair peer-review system, which is all easy to use. Visit http:// www.dovepress.com/testimonials.php to read real quotes from published authors. 